\title{
Promises, Pitfalls, and Pleasures of Practicing Evidence Based Psychiatry and Neurology
}

\author{
Andrew A. Nierenberg, MD
}

\begin{abstract}
"[Physicians] were not prepared to discard therapies validated by both tradition and their own experience on account of somebody else's numbers."1
\end{abstract}

"[Doctors] make clinical decisions based on how the last patient did, how their friends are treating patients and what the latest article by an authority says they should do..." ${ }^{2}$

"Evidence based medicine is the conscientious, explicit, and judicious use of current best evidence in making decisions about the care of individual patients. The practice of evidence based medicine means integrating individual clinical expertise.with the best available external clinical evidence from systematic research." ${ }^{3}$

"The laudable goal of making clinical decisions based on evidence can be impaired by the restricted quality and scope of what is collected as 'best available evidence'". ${ }^{4}$

Easy to mandate and difficult to implement, principles of evidence-based medicine (EBM) applied to psychiatry and neurology provide much promise but also many pitfalls. On one hand, clinicians' judicious use of EBM can inform clinical decision making; on the other hand, EBM can be misused "as a stick by which policy-makers and academics beat clinicians". ${ }^{5}$ Frequently missing from EBM discussions is a critical appraisal of the quality and quantity of available evidence.

EBM was imported to the United States from France in 1835 with the formation of the Boston Society of Medical Observation at the Massachusetts General Hospital. Luminaries of American medicine, including Oliver Wendel Holmes, were intrigued by Pierre Charles Alexandre Louis' numerical method that cast doubt on the efficacy of blood letting to treat inflammatory diseases. ${ }^{6}$ Nevertheless, clinical observations and expertise, along with opinions from thought leaders, ie "eminence based medicine $", 7$ continued as the basis of medicine until the advent of double-blind, randomized controlled clinical trials (RCTs) championed by Sir Austin Bradford Hill in $1952 .{ }^{8}$ In 1955, Tom Chalmers was among the first modern researchers who challenged opinion as fact. He was a proponent of randomization to decrease bias and meta-analyses to integrate findings. ${ }^{2,9}$ Alvan Feinstein and others applied principles of epidemiology to clini-

Dr. Nierenberg is professor of psychiatry at Harvard Medical School, co-director of the Bipolar Clinic and Research Program, and associate director of the Depression Clinical and Research Program at Massachusetts General Hospital (MGH) in Boston.

Faculty Disclosures: Dr. Nierenberg consulted to or served on the advisory boards of Abbott, Appliance Computing, Inc., Brain Cells, Inc., BristolMyers Squibb, Eli Lilly, EpiQ, Forest, GlaxoSmithKline, Janssen, Jazz, Merck, Novartis, Pamlab, Pfizer, PGx Health, Pharmaceutica, Schering-Plough, Sepracor, Shire, Somerset, Takeda, and Targacept; he has received research support from Cederroth, Cyberonics, Forest, Medironics, NARSAD, the NIMH, Ortho-McNeil-Janssen, Pamlab, Pfizer, Shire, and the Stanley Foundation through the Broad Institute; he has received past support from BristolMyers Squibb, Cederroth, Eli Lilly, Forest, GlaxoSmithKline, Janssen, Pfizer, Lictwer Pharma, and Wyeth; he has received honoraria from the MGH Psychiatry Academy (MGHPA activities are supported through Independent Medical Education grants from AstraZeneca, Eli Lilly, and Janssen; he earns fees for editorial functions for CNS Spectrums through MBL Communications, Inc., and Psychiatric Annals through Slack, Inc.; he receives honoraria as a CME Executive Director for the Journal of Clinical Psychiatry through Physicians Postgraduate Press; he has been on the speaker's bureaus of Bristol-Myers Squibb, Cyberonics, Eli Lilly, Forest, GlaxoSmithKline, and Wyeth; he has received royalties from Cambridge University Press and Belvoir Publishing; he owns stock options in Appliance Computing, Inc.; and owns the copyrights to the Clinical Positive Affect Scale and the MGH Structured Clinical Interview for the Montgomery Asberg Depression Scale, exclusively licensed to the MGH Clinical Trials Network and Institute.

Acknowledgement: I would like to thank Katherine A. Philips, MD for her expert editing and critical thinking about this editorial. 
cal research as a basic science of clinical medicine that could inform clinical decisions. ${ }^{10}$ The rubric of EBM was resurrected and disseminated by David Sackett (influenced by Tom Chalmers) and colleagues in Canada in the 1990's., 11,12 Their center for EBM continues to have influence.

EBM sounds good, but here is where the difficulty resides: Because the majority of published RCTs are designed by pharmaceutical companies for approval of medications by regulatory agencies, and not designed to inform clinical care, much of the available evidence fails to inform every-day clinical decisions.

RCTs that test a new intervention or a new indication for an existing intervention, known as efficacy or explanatory trials, ask a specific question: does the intervention change the target of interest? ${ }^{13,14}$ Usually structured as a placebo or active controlled study with extensive and strict inclusion and exclusion criteria, these trials are designed to detect a signal compared to active treatment or placebo. These trials generate information such as the statistical significance of the difference in changes in a depression symptom scale for a new antidepressant compared to placebo. ${ }^{15}$

Pragmatic (effectiveness) trials address a different question: does the intervention work in real-world clinical practice? Pragmatic trials can be informative in ways distinct from efficacy or explanatory trials by informing clinicians' decisions. ${ }^{15}$ Pragmatic trials employ methods that would not usually be accepted for efficacy trials (eg, open treatment with the research clinician and participant knowing the treatment assignment as well as inclusion of a broad spectrum of comorbid conditions). These studies, if well designed, usefully inform clinical decisions. If poorly designed, with too many sites, with too few participants at each site, with too many strata that dilute interpretation because cells are empty, and with too many outcomes, then these studies can lead to misinterpretation of the data. This is especially so if readers interpret the lack of statistical significance as evidence of the absence of a difference as opposed to absence of evidence of a difference..$^{16}$ For example, the CATIE trial for schizophrenia found no statistically significant difference between several antipsychotics but this does not mean that a difference does not exist.

Reviews frequently rank the quality of evidence for EBM, placing RTCs at the top of the hierarchy and most of these are efficacy trials (see Cochrane
Reviews and BMJ Evidence series). Randomization reduces particular types of biases, specifically treatment by indication, susceptibility bias, and ascertainment biases. But as Feinstein wrote:

"Randomization is not a scientific method; it is an invaluable statistical strategy for the mathematical exploitation of uncertainty"17

Frequently missing from the assessment of evidence is the evaluation of invitation bias (did clinicians refer specific patients and not others to participate in studies? If so, were the more severely ill systematically excluded by researchers because compassionate researchers did not want to expose them to placebo?) and volunteer bias (of those who responded to an advertisement to participate in clinical research, were screened, and who agreed to randomization, including exposure to placebo, and subsequently allowed to enter the study, how much did they differ from the spectrum of patients seen in clinical settings?). We face the additional problem that studies can't study all patients and all clinical problems.

Where do these clinical epistemiological challenges leave us clinicians? They leave us having to use all sources of the best evidence in the best way that we can. They leave us with the pleasures of lifelong challenges to critically appraise evidence, to read key studies and meta-analyses with great care and attention to detail. They leave us with the need to maintain an attitude of healthy skepticism while avoiding extreme nihilism (eg, scientific data are useless, no one knows anything about anything, and doctors consistently make bad decisions). Finally, they leave us with a desire to always improve and grow our knowledge and clinical skills. A desire for growth, by the way, consistent with our psychological well being. ${ }^{18,19}$ CNS

\section{REFERENCES}

1. Warner JH. Attitudes to Foreign Knowledge. In: The Therapeutic Perspective: Medical Practice, Knowledge, and Identity in America, 1820-1835. Cambridge, MA: Harvard University Press; 1986.

2. Maclure M. Dr. Tom Chalmers, 1917-1995: The trials of a randomizer. CMAJ 1996;155:757-760.

3. Sackett DL, Rosenberg WM, Gray JA, Haynes RB, Richardson WS. Evidence based medicine: what it is and what it isn't. BMJ. 1996;312:71-72.

4. Feinstein AR, Horwitz Pl. Problems in the"Evidence" of "Evidence Based Medicine". Am J Med. 1997; 103:529-535.

5. Williams DDR, Garner J. The case against the evidence': a different perspective on evidence-based medicine. Br J Psychiatry. 2002;180:8-12.

6. Louis PCA. Researches on the effects of blood-letting in some inflammatory diseases, and on the influence of tartarised antimony and vesication in pneumonitis. Am J Med Sci. 1836;18:102-111. 
7. Isaacs D. Fitzgerald D. Seven alternatives to evidence based medicine. BMJ. 1999;319:1618

8. Hill AB. The clinical trial. N Engl J Med. 1952;247:113-119.

9. Chalmers TC, Eckhardt RD, Reynolds WE, et al. The treatment of acute infectious hepatitis. Controlled studies of the effects of diet, rest, and physical reconditioning on the acute course of the disease and on the incidence of relapses and residual abnormalities. J Clin Invest. 1955;34:1163-1235.

10. Feinstein AR. Clinical Epidemiology: The Architecture of Clinical Research, 2nd edition. Philadelphia, PA: W.B. Saunders Company; 1985

11. Sackett DL, Rosenberg WM. On the need for evidence-based medicine. J Public Health Med. 1995; 17:330-334.

12. Rangachari PK. Evidence-based medicine: old French wine with a new Canadian label? $J R$ Soc Med. 1997:90:280-284.

13. Zwarenstein M, Treweek S. What kind of randomized trials do we need? J Clin Epidemiol. 2009:62:461-463

14. Schwartz D, Lellouch J. Explanatory and Pragmatic Attitudes in Therapeutical Trials. J Clin Epidemiol. 2009:62:499-505.

15. Maclure M. Explaining pragmatic trials to pragmatic policymakers. J Clin Epidemiol. 2009:62:476-478

16. Kraemer HC, Glick ID, Klein DF. Clinical Trials Design Lessons From the CATIE Study. Am J Psychiatry. 2009;166:1222-1228.
17. Feinstein AR. "Clinical Judgment" revisited: The distraction of quantitative models Ann Intern Med. 1994;120:799-805

18. Ryff CD. Happiness is everything, or is it? Explorations on the meaning of psychological well-being. J Personality Soc Psychology. 1989;57:1069-81.

19. Ryff CD, Singer B. Psychological well-being: meaning, measurement, and implications for psychotherapy research. Psychother Psychosom. 1996;65:14-23.

\section{ERRATUM}

In a September 2009 supplement to CNS Spectrums (2009; 14(9): 1-7), it was incorrectly stated that Lexapro (escitalopram) has been available in generic form since May 2006.

Lexapro is not currently available in generic form and Forest Laboratories retains patent exclusivity through March 2012.

CNS Spectrums regrets and apologizes for the error.

\title{
Now Available Online at www.cnsspectrums.com CME-ACCREDITED SUPPLEMENT

\section{Clinical Management of Major Depressive Disorder}

\author{
Laurence Mignon, PhD and Stephen M. Stahl, MD, PhD
}

To request a print supplement, please e-mail ks@mblcommunications.com

This activity is sponsored by Neuroscience Education Institute and supported by an educational grant from Lilly USA, LLC. 